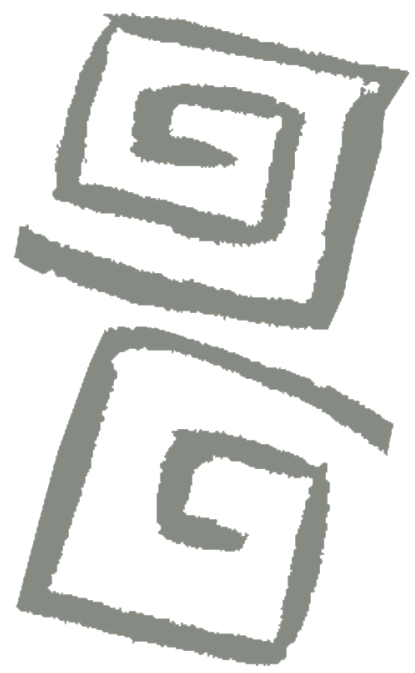

\title{
"Aquí (en Sídney) estamos perdidos": estudio etnográfico de la satisfacción vital de aborígenes urbanos australianos participantes en un programa sociocomunitario
}

\author{
"Here (in Sydney) we are lost:" An ethnographic study \\ of life satisfaction among urban aboriginal Australians \\ participating in a community outreach program
}

Juan Palomares-Cuadros ${ }^{1}$, Jorge Marcos-Marcos ${ }^{2}$, Alfonso Marquina-Márquez ${ }^{3}$

${ }^{1}$ Doctor en Educación Física. Investigador, Grupo HUM-727, Universidad de Granada, Granada, España. $\triangle$ id

${ }^{2}$ Autor de correspondencia. Doctor en Estudios de Género. Docente Departamento de Psicología de la Salud, Universidad de Alicante. Investigador, Grupo de Investigación en Psicología Aplicada a la Salud y Comportamiento Humano (PSYBHE), Universidad de Alicante, Alicante, España. $\square$ (iD

${ }^{3}$ Doctor en Antropología de la Salud. Profesor, Departamento de Sociología y Trabajo Social, Universidad de Valladolid, Valladolid, España. Investigador, Grupo de Investigación en Estudios Socioculturales Aplicados (SEJ208), Universidad de Granada, Granada, España. $\triangle$ (iD)
RESUMEN Este estudio etnográfico fue diseñado para explorar las condiciones de vida de un grupo de familias aborígenes residentes en un contexto urbano, beneficiarias de un programa sociorecreativo en Sídney, Australia. El objetivo fue explorar la satisfacción vital mediante el análisis de sus condiciones de vida y del capital cultural inscrito en sus actitudes, percepciones y conocimientos establecidos. El trabajo de campo se estructuró en dos fases complementarias: en la fase 1, entre mayo de 2008 y diciembre de 2010, se inició con el ingreso del primer autor como voluntario en la asociación responsable del programa y, en la fase 2, entre enero de 2011 y febrero de 2013 se intensificó el proceso de observación participante y las entrevistas semiestructuradas. Los resultados muestran que el proceso de desarraigo cultural está en la base de las experiencias vitales de desigualdad social experimentadas y apunta a un efecto de cohorte que llega hasta nuestros días. Dicho proceso de (des)consonancia cultural debe ser tenido en cuenta como un factor clave a la hora de analizar las condiciones de vida y bienestar de estas minorías étnicas, así como a la hora de desarrollar programas e intervenciones.

PALABRAS CLAVES Grupos Minoritarios; Calidad de Vida; Determinantes Sociales de la Salud; Inequidad Social; Australia.

\begin{abstract}
This ethnographic study was designed to explore living conditions among a group of aboriginal families residing in an urban context, who participated in a recreational social program. The aim of the study was to explore life satisfaction by analyzing their living conditions and cultural capital inscribed in established attitudes, perceptions, and lay knowledge. Fieldwork was carried out in two complementary phases: phase 1, between May 2008 and December 2010, began when the first listed author initiated volunteer work with the organization responsible for the program; in phase 2, which extended from January 2011 to February 2013, participant observation was intensified and semi-structured interviews were carried out. The results indicate that the process of cultural uprooting underscores the experience of social inequality, and suggest a cohort effect that continues to this day. This process of cultural (in)consonance must be taken into account as a key factor when analyzing the living conditions and well-being of ethnic minorities, as well as when developing programs and interventions.
\end{abstract}

KEY WORDS Minority Groups; Quality of Life; Social Determinants of Health; Social Inequity; Australia. 


\section{INTRODUCCIÓN}

Al describir las desigualdades sociales en términos de bienestar, calidad de vida y satisfacción vital entre distintos grupos de personas dentro de un mismo contexto cultural, la bibliografía científica ha puesto de manifiesto que las poblaciones indígenas experimentan mayores niveles de desigualdad ${ }^{(1,2,3)}$. En el caso de la población aborigen australiana, la esperanza de vida es de 10,6 años menor para los hombres y 9,5 para las mujeres, con respecto a la población no-aborigen ${ }^{(4)}$. A esto hay que sumar que aunque los indicadores de bienestar y la calidad de vida de los aborígenes australianos, incluidos los isleños del Estrecho de Torres, apuntan a una mejora a lo largo de las últimas décadas, los aborígenes siguen siendo el grupo más desfavorecido de Australia: tienen las cifras más altas de desempleo, los niveles más bajos de ingresos económicos, el mayor número de población en prisión, los niveles más altos de enfermedades infecciosas y crónicas, así como un elevado consumo de drogas y de casos de violencia familiar ${ }^{(5,6)}$. En este sentido, la brecha social existente entre aborígenes y noaborígenes se ha intensificado a lo largo de los últimos años dentro de la sociedad australiana ${ }^{(7)}$.

De forma general, estos hechos han llevado a poner énfasis en dos clases de influencia, inextricablemente conectadas, cuando se analizan las desigualdades desde la perspectiva del bienestar y los determinantes sociales de la salud ${ }^{(8)}$. Por un lado, la existencia de una posición de desventaja social y, por el otro, su posición marginal con relación a la sociedad en general ${ }^{(9)}$. En el caso concreto de los aborígenes de Australia, conceptualizar esta situación implica tomar en consideración, en primer lugar, las consecuencias de políticas planteadas durante el siglo pasado. En este sentido, se pueden subrayar dos procesos claves a la hora de entender la historia social de estas poblaciones: haber sido partícipes de "la generación robada" y, en muchos casos, verse expuestos a un proceso de adaptación al medio urbano(10).
La consideración a las generaciones robadas (the stolen generations) remite a una de las decisiones políticas que más ha influido en la situación social actual de la comunidad aborigen en Australia ${ }^{(11)}$. Hasta 1970, cualquier niño o niña aborigen que tuviera en su descendencia algún miembro no-aborigen, los conocidos como "media casta", eran separados de su familia y llevados a un orfanato. El objetivo era instruirlos para poder ser integrados, como mano de obra, en las nuevas y crecientes sociedades urbanas australianas $^{(12,13)}$. Este proceso sociopolítico está en la raíz del surgimiento de determinados barrios, los cuales comenzaron a caracterizarse por ser zonas habitadas por aborígenes, media casta principalmente, procedentes de diferentes misiones. A medida que estos barrios empezaron a crecer, se empezó a poner en evidencia las situaciones de segregación concentración de pobreza y demás problemáticas sociales asociadas ${ }^{(14,15)}$. A esto hay que sumar el proceso de dependencia generado por el Estado que, si bien les ha brindado el acceso a determinados servicios sociales, incluidos la vivienda, un número creciente de personas expertas considera que se les ha despojado de su autonomía personal, poniendo de manifiesto la necesidad de hacer confluir la asunción de la identidad étnica, con el hecho de participar como miembros activos y de pleno derecho en la sociedad australiana ${ }^{(13)}$. En las últimas décadas, el gobierno australiano ha tenido un mayor compromiso en el desarrollo de intervenciones para tratar de reducir las brechas existentes en la salud y bienestar de las poblaciones aborígenes en Australia ${ }^{(6)}$. Este compromiso se conoce como "closing the gap" en el marco de la Agenda de reforma indígena del Council of Australian Governments (COAG).

Entre las medidas emergentes para paliar las carencias de estas poblaciones urbanas surgió una creciente implementación de programas sociorecreativos, diseñados con el objetivo de mejorar la calidad de vida y la inclusión social de las comunidades aborígenes ${ }^{(16,17,18)}$. A lo largo de los últimos años, la bibliografía científica ha ido generando un corpus cada vez más sólido de evidencias 
sobre el impacto positivo, a nivel biopsicosocial, que supone incorporar prácticas imbricadas a representaciones tradicionales de la identidad cultural a los programas de intervención comunitaria ${ }^{(17,18,19,20,21)}$. En el caso concreto de las poblaciones aborígenes, han sido de especial interés los programas específicos con fines lúdico-recreativos, conectados a áreas como la educación y la integración social| ${ }^{21,22)}$. Igualmente, estos programas también han contribuido al tratamiento de la identidad cultural, que se identifica como un elemento clave en procesos resilientes de desarrollo de factores protectores para la salud y el bienestar a nivel individual y comunitario $^{(2,23)}$. En este sentido, constituyen ejemplos de interés los estudios que muestran cómo la incorporación de actividades culturales tradicionales en programas comunitarios favorece el desarrollo de capital social, incidiendo en aspectos como la reducción de las tasas de violencia, suicidio y depresión ${ }^{(24)}$, o favoreciendo un consumo no problemático de alcohol y otras sustancias psicoactivas ${ }^{(25,26)}$. De ahí que los programas de integración, dirigidos a poblaciones aborígenes, suelan estar diseñados desde un enfoque psicosocial, dada la exposición a situaciones de vulnerabilidad asociadas a traumas históricos, relacionados con los procesos de integración versus asimilación cultural ${ }^{(25,27)}$.

Para conocer el impacto de estos programas, la tendencia ha sido tomar en consideración la influencia de la estratificación social en factores como la posición socioeconómica. Sin embargo, estamos ante un elemento estructural cuya contribución a las desigualdades sociales no debería considerarse únicamente en el plano personalsubjetivo. Así, por ejemplo, en poblaciones urbanas, no solo diferentes estudios muestran la peor salud percibida entre las familias de barrios pobres ${ }^{(28,29)}$, sino también, que los efectos sobre la salud de la privación de un barrio no son completamente compositivos, sino parcialmente contextuales ${ }^{(30)}$. Sin embargo, la atención no debe ser puesta únicamente en el análisis socioeconómico. En el análisis sobre el impacto de los programas comunitarios, la perspectiva del capital social también resulta de gran utilidad, dada la relevancia de los factores colectivos como, por ejemplo, las relaciones informales de confianza y cooperación, la asociatividad formal en organizaciones de diverso tipo o el marco institucional normativo y de valores de una sociedad, los cuales fomentan o inhiben las relaciones de confianza y compromiso cívico $^{(31,32)}$. De este modo, si la interacción entre el capital económico y social ha recibido cada vez más atención en la bibliografía científica, a menudo no se ha tomado en consideración el papel jugado por el capital cultural en la producción de desigualdades sociales. Esto es, el conjunto de habilidades operativas, capacidades comunicativas, sistema de valores y códigos normativos incorporados a través de distintos procesos de socialización ${ }^{(33)}$.

Este trabajo nace del convencimiento de que conjugar el logro de equidad y efectividad en las intervenciones públicas, implica necesariamente comprender tanto las dinámicas e interacciones culturales que caracterizan a un determinado contexto, como los factores y mecanismos por los que se generan y reproducen las desigualdades. Para ello, se hace necesario explorar las experiencias individuales y colectivas relativas al capital cultural, y sus conexiones con las desigualdades sociales. La naturaleza multifactorial de dichas desigualdades hace necesario un conocimiento más profundo de los factores de riesgo social, cultural e histórico, que solo conocen las propias personas afectadas conocen ${ }^{(20)}$.

Al concebir las desigualdades sociales como un entramado de causas, en su abordaje cobran especial importancia la consideración hacia planteamientos metodológicos cualitativos. Este estudio se fundamenta en el seguimiento a una comunidad aborigen a través de la participación en un programa sociorecreativo desarrollado por una asociación, en un barrio del centro de Sídney, donde las familias aborígenes, provenientes de diferentes grupos étnicos y lugares del país, se asentaron a lo largo de las últimas décadas del siglo pasado. El programa fue establecido para contribuir en una doble vertiente: por 
un lado, promover la práctica de actividades físico-recreativas y, por el otro, asesorar a las familias sobre recursos y servicios públicos disponibles. El objetivo de este artículo es explorar la satisfacción vital, como percepción subjetiva de bienestar y calidad de vida, de un grupo de aborígenes urbanos beneficiarios de un programa sociocomunitario, mediante la identificación de componentes del capital cultural inscritos en sus actitudes, percepciones, conocimientos y valores.

\section{MÉTODOS}

Este trabajo está basado en un estudio etnográfico, cuyo trabajo de campo se desarrolló entre mayo de 2008 y febrero de 2013 en Sídney (Australia). El trabajo gira en torno a las actividades sociorecreativas planteadas por una asociación sin ánimo de lucro que trabaja en un barrio del centro de la ciudad.

El trabajo de campo fue estructurado en dos fases complementarias. La fase 1 se llevó a cabo durante 20 meses, entre mayo de 2008 y diciembre de 2010, iniciándose con el ingreso del primer autor como voluntario en la asociación responsable del programa. En dicha fase tuvo lugar el contacto con el programa sociorecreativo, así como el proceso de negociación de acceso a las familias aborígenes; concretamente, en el establecimiento de relaciones de confianza. Esto implicó un proceso de selección de las familias participantes. De las 15 familias involucradas en el programa, se seleccionaron las seis que asistían con regularidad a las actividades planificadas. Dichas familias nos proporcionaron una muestra de 54 personas.

El desarrollo de este proceso puso de manifiesto el choque cultural entre las familias aborígenes y el investigador principal, de origen español. Sin embargo, este hecho favoreció el proceso de aceptación por parte las familias aborígenes. En este caso, la consideración de extranjero, la apariencia física y el hecho de no hablar un inglés nativo, fueron elementos que contribuyeron a facilitar el hecho de empezar a compartir anécdotas y situaciones personales a un nivel de confianza que la mayoría de los voluntarios australianos no-aborígenes no había conseguido. Este fue un periodo de recolección de información proveniente de un análisis documental (bibliografía científica y no científica, noticias periodísticas y documentales etnográficos), así como de observación, observación-participante y conversaciones informales. Todas las notas de campo generadas a lo largo de esta fase, así como los memorandos analíticos grabados en audio tras las sesiones compartidas con el grupo, fueron transcritos. Esto se hacía normalmente el mismo día en que eran realizadas, organizándolas mediante la asignación de un código inductivo preliminar. El análisis temático de esta primera fase sirvió para establecer el guión de entrevista que sería aplicado durante la segunda fase del trabajo de campo.

La fase 2 del trabajo de campo se desarrolló entre enero de 2011 y febrero de 2013. Durante esta fase se intensificó el proceso de observación participante y se implementó el protocolo de entrevistas semiestructuradas en los propios hogares de los participantes aborígenes. Dicho protocolo estuvo fundamentalmente orientado al entendimiento de sus trayectorias sociales y sus condiciones de vida desde lo personal, lo familiar y lo comunitario. El proceso estuvo en todo momento orientado al descubrimiento, comenzando a menudo las entrevistas a modo de relato biográfico. La mayoría de los participantes fueron entrevistados al menos dos veces. Del mismo modo, los datos fueron en todo momento complementados con sucesivas conversaciones informales. Dicho proceso de complementariedad y triangulación de información se hizo extensible a seis informantes claves (aborígenes y no-aborígenes), relacionados con el programa comunitario, y que fueron consultados de forma regular a lo largo de todo el trabajo de campo.

La combinación de técnicas e informantes permitió una exploración más profunda de los factores sociales-culturales y de aspectos personales en relación al objeto de estudio. Las entrevistas informales fueron particularmente útiles en la identificación de 
percepciones establecidas en torno a expectativas, manifestaciones de deseabilidad social y comportamientos considerados apropiados. Las entrevistas individuales permitieron ahondar en las percepciones y conocimientos establecidos de los participantes sobre la imbricación de los aspectos culturales y relacionales con las dimensiones organizacionales del programa socio-recreativo. En el caso de las entrevistas con los informantes claves, dando cabida a un rol más activo del entrevistador-investigador en la discusión, sirvieron como una forma de confrontar más exhaustivamente ciertas perspectivas recurrentes.

Se llevó a cabo un análisis de contenido convencional ${ }^{(34)}$. Tras la primera lectura general del material transcrito, se identificaron los temas emergentes, estableciéndose las dimensiones y subdimensiones de análisis. La clasificación conceptual de los códigos y las categorías se construyeron siguiendo un procedimiento tanto deductivo como inductivo. El proceso se inició con una lista predeterminada de temas a ser explorados y un esquema de categorías previamente determinados. Sin embargo, cualquier categoría o subcategoría emergente durante el proceso de examen de los resultados fue incorporada al análisis. Todo el proceso de generación de conceptos y categorías, así como el proceso de codificación, fue realizado por el investigador principal en colaboración con los otros miembros del equipo. Este proceso de triangulación fue llevado a cabo para añadir una mayor confiabilidad al análisis.

El equipo, conformado por investigadores españoles, tuvo presente desde un primer momento las implicaciones éticas de un proceso de investigación de estas características, en contacto con poblaciones en situación vulnerabilidad social. El proyecto fue aprobado por el Comité de Ética de la Universidad de Granada (España). Además, en cumplimiento de los principios éticos expresados en la Declaración de Helsinki y las legislaciones vigentes en Australia( ${ }^{(35)}$ y España ${ }^{(36)}$, los datos personales de todas las personas participantes fueron guardados en un fichero de seguridad y los nombres reales reemplazados por otros ficticios a fin de garantizar su anonimato.
La participación fue voluntaria, teniendo en todo momento las personas informantes la libertad de decidir si querían responder a lo que se les preguntaba. El consentimiento informado no fue recogido por escrito, quedando constancia de dicha conformidad en las distintas grabaciones de audio; estrategia que contó con la aprobación de líderes de la comunidad. En cualquier caso, todas las personas fueron informadas de los objetivos del estudio, recibiendo el compromiso por parte del equipo de investigación de que los datos obtenidos serían utilizados para fines académicos con el máximo rigor, respecto y confidencialidad.

\section{RESULTADOS}

Los resultados de este estudio ponen de manifiesto un conjunto de aspectos que, relacionados con el capital cultural y la satisfacción vital, apuntan a un desajuste en la consonancia cultural experimentada por la población aborigen participante en el estudio, y que directa o indirectamente fueron relacionadas con sus condiciones y estilo de vida. Concretamente, de los resultados emergen tres temas principales imbricados a la identidad grupal y la integración social de población aborigen urbana objeto de estudio, y que se exponen en relación con la influencia de programas comunitarios como el que sirvió de hilo conductor durante este trabajo.

\section{"Ellos no quieren saber nada de nuestro mundo, mientras nosotros intentamos sobrevivir en el suyo": trauma histórico y sentimiento de desposesión cultural}

Los resultados apuntan claramente a la existencia de un sentimiento de trauma histórico relacionado con el proceso de separación de su tierra de origen en el caso de los miembros de edad más avanzada, pertenecientes a una generación no nacida en Sídney. Dicho proceso de colonización ha dado como resultado una narrativa de nostalgia, que fue 
considerada, desde un punto de vista de los participantes, la causa de la causa de los riesgos psicosociales y las elevadas prevalencias de problemas de salud mental. En cualquier caso, de las narrativas se desprende que no siempre se refieren a este trauma como una condición patológica, sino como una metáfora por su relación histórica con la sociedad del colono europeo. Es precisamente dicha noción metafórica del trauma colectivo e intergeneracional la que permite significar una vía para la comprensión de los problemas sociales contemporáneos mediante procesos históricos personificados en el proceso de colonialismo. Este sentimiento de trauma histórico fue mayoritariamente expresado en términos de sufrimiento y sometimiento por parte de los participantes aborígenes de mayor edad:

Recuerdo que mi padre me contaba cómo, con la llegada de los blancos, la vida de mi familia cambió considerablemente, perdimos la tierra, los lugares sagrados, nuestra forma de vida y los lugares de recolección de frutas. Fuimos desplazados a los lugares donde había granjas y ganaderías cerca de las estaciones de tren. Fuimos obligados a ir a la escuela y a la iglesia en la misión, -ite imaginas?- No podíamos salir de la misión sin permiso, algunas mujeres se casaban con blancos para escapar de allí. No conocían nuestra cultura y nuestras tradiciones y no nos respetaban, siempre escuchaba estas frases en mi familia: ¡Solo querían que fuésemos como ellos! (Darel, hombre, 62 años)

En este fragmento narrativo el aborigen informante se muestra como una víctima que "arrancan de su cultura" y su comunidad para llevárselo a un contexto extraño y "transformarlo" en un whiteman. En este sentido, la integración de la historia colonial, en términos pragmáticos, puede entenderse como una práctica discursiva que, al presentar el trauma histórico mediante narrativas de desposesión y nostalgia, ofrece un camino de agencia individual para la resistencia, que permite reconceptualizar el problema en términos socioestructurales y no solo psicopersonales.

El hecho de explicar sus aflicciones en este sentido, como población despojada de identidad cultural, hizo que emergiera en los participantes un conocimiento establecido sobre el impacto que en sus vidas ha tenido el afrontamiento de situaciones tales como la adaptación a un entorno urbano, crecer en internados escolares $y$, en general, verse abocados a situaciones de marginalización o de desventaja social, cuya causa fundamental consideran que tiene que ver con tener que afrontar un sistema de valores radicalmente opuesto al de sus raíces, especialmente, en lo que respecta a la cultura individualista; una vida alienada al ideal animista de la sociedad aborigen tradicional, que ha generado una pérdida de significado en la vida y que, además, parece haber tenido un efecto intergeneracional. Por ejemplo, esto queda patente en sus experiencias de desestructuración familiar, que aún perviven en su memoria, especialmente en el caso de la separación de los miembros de una de las familias participantes en el estudio, en la que existía la figura de media casta.

Otro elemento clave del sentimiento de desposesión es la pérdida de la lengua materna aborigen, un marcador de identidad cultural que emergió de manera recurrente en las narrativas. Los adultos que no han nacido y crecido en su tierra de origen conocen algunas expresiones y palabras, pero ya no pueden expresarse y carecen de los vínculos intrínsecos que proporciona la lengua materna. La lengua que prevalece en sus hijos es una mezcla del inglés australiano con léxico aborigen, y este lenguaje peculiar es la forma de comunicación, tanto familiar como social. Los resultados apuntan a que entre las causas de la pérdida de la lengua aborigen se encuentra la acción de los propios médicos y docentes de los centros donde tenían que llevar a sus hijos e hijas, al haberles desaconsejado utilizar su lengua de origen como forma de evitar los problemas de aprendizaje que esto podría causarles. Así lo expresó una de nuestras informantes aborígenes. 
...nuestros hijos no se expresan en inglés como los no-aborígenes. Nos dijeron que debíamos dejar de enseñarle nuestra lengua, que es la que hablaba mi madre conmigo, pero ni a mí ni a ellos, sobre todo a ellos, les han ayudado en el colegio para que la hablasen como los nativos, el inglés es una barrera para vivir en Sídney y la escuela no les ayuda lo suficiente... (Sahani, mujer, 42 años)

Del mismo modo, solo en algunos casos afirmaron mantener su espiritualidad tradicional. Aunque, en general, se perciben ciertos aspectos espirituales en la forma de comportarse, solo en algunos casos retornan a su lugar de origen para algunas celebraciones y rituales, con las que los hijos ya no tienen ningún vínculo. En cualquier caso, la amplia mayoría de nuestros participantes se reconocen como cristianos, aunque al hablar de dicho sistema de creencias las narrativas se orientaba fundamentalmente a los beneficios y ayudas que esto les comporta. Esta situación fue expresada por Dainan, uno de los participantes que sí consideraba mantener su espiritualidad y conectividad con la tierra.

\footnotetext{
...en general, las tradiciones espirituales no se siguen en la ciudad, a mí me gusta ir a mi tierra, mi familia mantiene sus tradiciones. En cambio, aquí los que se van a la iglesia es porque reciben ayudas: ropa, comida e incluso medicamentos. En realidad, estas familias han perdido la espiritualidad tradicional... (Dainan, hombre, 52 años)
}

Los extractos seleccionados son indicativos de la reestructuración de las sociedades aborígenes en misiones durante el siglo XX, y dan muestra del proceso de conversión afrontado durante décadas, modificando ampliamente sus costumbres y valores. Todo esto emerge de los resultados como un componente crucial en la reproducción social de determinadas desigualdades en salud a través de comportamientos y estilos de vida específicos que estarían contribuyendo a sus peores resultados en salud, como las propias personas responsables del programa llegaron a poner de manifiesto. En este sentido, el consumo de alcohol y otras drogas adquiere una consideración clave. Aunque en las familias seguidas durante este periodo de tiempo existen realidades dispares, se evidencia claramente cómo en las familias en las que no existía un consumo problemático de alcohol u otras sustancias psicoactivas, las relaciones entre sus propios miembros y con el resto de familias eran más positivas, con una mejor comunicación y una red de apoyo más fuerte. En cualquier caso, a lo largo del trabajo de campo se recopilaron, por ejemplo, numerosos episodios de violencia relacionados con el consumo de drogas. En el siguiente extracto de entrevista, Darel muestra cómo, en primera instancia, al llegar a la ciudad, Ilegó a desarroIlar conductas disruptivas como parte de un proceso de adaptación y búsqueda de sentirse integrado dentro de algún colectivo.

...al llegar, cuando empezábamos a conocer los alrededores, comenzamos a ir a un pub del barrio donde había muchos grupos de moteros que se juntaban a beber alcohol. Matthew y yo comenzamos a beber también ahí. Yo quería ser parte de uno de estos grupos, e incluso comencé a vestir como ellos (risas). Cuando estaban borrachos solían comenzar las peleas. Muchas veces las peleas ni siquiera tenían sentido. Matthew y yo solíamos volver a casa bastante borrachos y comenzábamos a tener un comportamiento bastante antisocial y violento. Un día nos echaron del bar y a la salida le rompí la mandíbula a una persona de un golpe. Llamaron a la policía y me metieron en la cárcel. (Darel, hombre, 62 años)

\section{"No se les pasa por la cabeza pensar que habría que ir dándoles más autonomía y responsabilidad": implicaciones de la falta de autodeterminación}

La consecuencia directa de la percepción de este "trauma" ha sido vivir bajo el estigma 
social, además de una identidad marcada por un estatus devaluado, que se refleja especialmente en la baja autoestima y falta de proactividad. De este modo, el alejamiento de la cultura ancestral y el no respeto por la tradición ha hecho que, comunidades aborígenes como la estudiada, se perciban a sí mismos como un pueblo débil y dependiente.

Las personas aborígenes participantes en el programa consideraban de forma mayoritaria que no tenían participación en la gestión de las actividades desarrolladas; esta percepción establecida de su pasividad dentro del programa conectaba claramente con la asunción de un rol de receptores pasivos. Aunque en la amplia mayoría de las entrevistas y conversaciones informales no se refirieron a esta situación de forma especialmente crítica, sí se recopilaron algunas voces en este sentido como, por ejemplo, la de Simón, que expuso este tema de la siguiente manera:

...sí, eso sería lo ideal, pero a los australianos les gusta sentirse capataces, jefes, organizadores, para que otros participen a su manera, y con sus reglas, incluso en esta actividad se puede ver, que todo está organizado. Isabel lo dispone, aunque lo hace con buena intención, no se les pasa por la cabeza pensar que habría que ir dándole más autonomía y responsabilidad, tienen que aprender a gestionar su responsabilidad. (Simon, hombre, 62 años)

La falta de promoción de la autodeterminación se puso de manifiesto en el hecho de que todos los sábados, después de la jornada de actividades programadas, se realizaba una reunión de reflexión y evaluación sobre la jornada, en la que solo participaban los voluntarios. En estas reuniones, en las se tomaban las decisiones de las actividades a realizar, se puedo comprobar cómo no se solía pedir opinión a las familias aborígenes sobre las actividades que les podrían resultar de mayor interés. De las entrevistas y conversaciones mantenidas con las personas que llevan a cabo el programa emerge, de forma recurrente, la idea de la falta de autonomía que estas familias aborígenes tienen en su propia vida cotidiana. Así lo expresó una voluntaria, incidiendo en las condiciones de vida y la tendencia de estas familias a estilos de vida perjudiciales para la salud:
¿Acaso no lo necesitan? ¿Cuál es el fin de este trabajo, sino ayudarles... De lo con- trario, en su tiempo libre se comportaría como cualquier otro australiano o ya sabéis, los niños pasando la mañana en la calle viendo a sus padres en muchos casos emborrachándose o fumando mari- huana... (Susan, mujer, 26 años)

Nuestros hallazgos apuntan a que los aborígenes son conscientes de ello, y se dejan gestionar por los beneficios que consideran que obtienen de las actividades realizadas, incluyendo los recursos recibidos o la asistencia para solicitar subvenciones y ayudas de carácter social. Además, tienen claro que algunos voluntarios participan en estas actividades porque les sirve para cubrir una asignatura de voluntariado, optativa durante el bachillerato o la universidad. En cualquier caso, algunos de los aborígenes entrevistados se refirieron explícitamente a que en verdad no les importaba mucho cuáles eran sus necesidades e intereses, y no se proponían transferir la toma de decisiones a las propias familias e involucrarlas más, porque ello podía repercutir en la propia función del voluntariado. En este sentido, otra de las razones identificadas con relación a la oposición de los voluntarios a las posibilidades de gestión de los aborígenes, tiene que ver con el hecho de que algunos voluntarios reciben dinero por realizar algunas actividades específicas. Así lo expresó una de nuestras informantes aborígenes, quien se preguntaba si no deberían ser ellos quienes tuvieran esa opción de percibir algún dinero.

Piensa compañero, ¿por qué Michael recibe $\$ 150$ por ser el encargado de la barbacoa? ¡Es blanco! Su novia es un cuarto aborigen, está integrada, viven como blancos, ¿él trabaja y estudia? ¿por qué no lo hace Heng? En su casa 
lo necesitan, el está de prácticas en una empresa y es el único de aquí que se le ve futuro. Además, Garbis, aunque ha caído en la droga, necesita como terapia tener responsabilidad, y es capaz de hacerlo también como los demás. (Aremi, mujer, 39 años)

Entre los pocos recursos que los jóvenes encuentran para ganar control sobre sus vidas, está practicar fútbol australiano (footy). No solo fue descrito en términos de refugio psicológico, sino también como una forma de revertir su situación de precariedad socioeconómica. En este sentido, los resultados ponen de manifiesto que existe una percepción establecida de que el hecho de ser aborígenes les proporciona mayor capacidad para triunfar en este deporte. Nuestros hallazgos apuntan a que esto parece actuar como un mecanismo que retroalimenta dicha fórmula para ganar prestigio social dentro de la sociedad australiana.

...estos niños tienen que aprender a jugar al footy [denominación del fútbol australiano] ellos tienen muchas capacidades ¡Corren más rápido que los aussi! [australianos de origen occidental]. Tiene que llegar al Koori Knockout Indigenous Rugby League, así se harán populares y saldrán en la tele también. (Kora, mujer, 49 años)

Aunque los padres y madres aborígenes pensaban que era muy positivo para sus hijos practicar footy dentro del programa, consideraban que el tiempo destinado a esta actividad era demasiado limitado. Por otro lado, en ningún caso las narrativas apuntaron a la importancia de esta actividad físico-deportiva como una herramienta para el mantenimiento y mejora de la salud; tampoco se contemplaba un camino alternativo para aquellos que no pudieran dedicarse profesionalmente a este deporte. Esto emergió como una diferencia especialmente significativa en las niñas. De hecho, cuando se les preguntaba a las adolescentes por sus estilos de vida, como el hecho de fumar, solían afirmar que una vez que crecían y dejaban de ser niñas, hacer actividad física dejaba de tener sentido para ellas, ya que no tenían posibilidad de triunfar en el mundo del deporte; además, fumar les hacía entrar en el "círculo de los mayores". De este modo, emergen valores y percepciones sobre los efectos en la salud de determinados comportamientos, los cuales se transforman en recursos culturales que dan forma a las preferencias y opciones de estas chicas, especialmente, en lo relativo a la adopción de estilos de vida no saludables.

\section{"Para nosotros esta forma de vida [urbana] no es natural": las actividades culturales tradicionales como metáfora salutogénica}

Las narrativas recogidas apuntan a una imagen recurrente de un pasado armónico con la naturaleza y de relaciones fuertemente cohesionadas entre las familias. Esta visión de interdependencia con el mundo natural y de cohesión interpersonal emerge de los resultados como la piedra angular de su bienestar. Una visión icónica que da lugar a una importante percepción establecida: "todo tiempo pasado fue mejor". Así lo expresaba uno de nuestros informantes, para quien sigue siendo importante mantenerse en contacto con las tradiciones ancestrales de su pueblo e involucrarse en actividades que lo mantengan en contacto con la naturaleza.

El problema es que aquí [en Sídney] no hacemos nada. Cuando voy a mi tierra [Aranda, en el centro de Australia] aún se sigue cazando, con rifle, ipero se caza!, $y$ se recogen frutos; es cierto que lo hacen los más viejos, ipero se hace! Los abuelos se preocupan de estas tradiciones... Aquí estamos perdidos. Mis hijos no les queda otra que estudiar y buscar trabajo; para nosotros esta forma de vida no es natural. Yo, ahora, me voy seis semanas a caballo, a conducir un rebaño de vacas por el centro de Australia. Ya sé que tampoco es tradicional, pero lo pre- 
fiero a estar aquí en la ciudad... (Daku, hombre, 47 años)

De este modo, la tierra (land), en la imagen cultural de Mother Earth (madre tierra), Ilega a ser descrita como un espacio ancestral y curativo, la experiencia de vivir el espacio natural como una fuente importante de identidad personal. Desde este punto de vista, los símbolos culturales como Mother Earth son medios expresivos y retóricos a través de los cuales cultivar una percepción del espacio natural como terapéutico. Esto hace que las actividades culturales tradicionales adquieran un significado especial, puesto que operan como un espacio simbólico que vertebra el mantenimiento de la identidad aborigen contemporánea; de ahí que el ocio culturalmente apropiado fuera un elemento enfatizado por los participantes como vía de salvaguardar una identidad positiva. De hecho, las familias aborígenes participantes en el programa destacaron la importancia y el bienestar que suponen las actividades culturales que evocan la forma de vida tradicional. Nuestros informantes adultos aludieron a prácticas de caza, pesca y recolección con tristeza, pensando en la pérdida de conocimientos y habilidades de sus jóvenes:

Recuerdo que íbamos a recoger frutas y también pescábamos en el río; no era fácil, pero siempre agarrábamos algo. Era como una competición entre los primos y tíos a ver quién agarraba más [...] ahora, estos chicos no saben de nada, no conocen estas conexiones con nuestra Mother Earth; no se lo hemos podido enseñar... me gusta cuando se organiza alguna actividad de pesca, porque en su espíritu aún debe quedar algún conocimiento. (Simon, hombre, 62 años)

Desconozco muchos juegos. Recuerdo jugar, cuando vivía con la familia, al Boogalah, un juego que jugábamos en círculo con una pelota de piel de canguro o de pósum, pero hace mucho tiempo que no..., ni tampoco he vuelto a ver a nadie jugar a esto. Hemos perdido nuestra lengua, nuestras tradiciones, y los juegos ni los conocemos nosotros, pues cómo los van a conocer nuestros hijos. (Dainan, hombre, 52 años)

Las actividades que se realizan tienen un objetivo claramente recreativo, estando especialmente orientadas para los más jóvenes. En este sentido, más allá del fútbol australiano, las actividades realizadas fuera del parque utilizado como espacio habitual, tales como actividades de senderismo, pesca o escalada deportiva, fueron sin duda las mejor valoradas por los adultos y jóvenes aborígenes del programa, por considerarse conectadas con sus raíces culturales. En cualquier caso, la percepción generalizada es que dichas actividades tienen cabida de una forma muy limitada en el programa.

\begin{abstract}
Vamos muy poco de pesca. Isabel no alquila muchas veces el barco, y solo vamos si hay barco. Lo de la pesca lo llevan en la sangre; les gusta, se sienten más seguros haciendo esta actividad, y aunque no es lo mismo que cuando yo era pequeña, en el fondo es igual... (Sahani, mujer, 42 años)
\end{abstract}

Pero, sin duda, las actividades recreativas que consideraban más importantes eran las que tenían que ver con narración de cuentos y leyendas de su mitología, danzas ancestrales y pinturas nativas. Nuestros resultados ponen de manifiesto que dichas actividades son especialmente valoradas no solo por considerarlas enraizadas en su cultura, sino porque son las que les permiten considerarse los protagonistas y expertos. El hecho de que percibieran a los no-aborígenes como desconocedores de estas prácticas se identificó como una fuente de autoestima y fortalecimiento de los vínculos interpersonales. Así nos lo expresó un voluntario del programa, que percibía que los más jóvenes necesitaban demostrarles a los "blancos" que ellos también era capaces de hacer cosas mejor que ellos y sentirse protagonistas. 
¡Observa! [viendo a dos voluntarios y un chico aborigen] realmente Sukru desconoce la pintura aborigen; posiblemente los dos voluntarios que están con él pintando tengan más idea y hayan visto más pinturas que él, pero el hecho de que es algo que pertenece a su cultura, le sirve para autosobrevalorarse y dirigir a los otros dos, sobre cómo deben de pintar: qué colores utilizar, qué signos hacer... (Cooper, hombre, 52 años)

\section{DISCUSIÓN}

Este estudio etnográfico fue diseñado para explorar las condiciones de vida de un grupo de familias aborígenes residentes en un contexto urbano, beneficiarias de un programa sociorecreativo. Los resultados ponen de manifiesto que la forma en que este colectivo de personas percibe sus condiciones de vida cotidiana y su satisfacción vital está fuertemente vinculada a un sentimiento de desarraigo directamente imbricado a la desapropiación de capital cultural. De forma general, esto emerge de nuestros resultados directamente relacionados con: 1) las competencias para afrontar sus problemas cotidianos, que influyen en las propias expectativas de futuro, y 2) la importancia concedida al desarrollo de actividades culturales tradicionales dentro del programa comunitario.

Basado en las narrativas de los participantes en nuestro estudio, la población aborigen expresa un sufrimiento, que es principalmente resultado de problemas modernos ocasionados por el estrés aculturativo y las desigualdades sociales que tuvieron que enfrentar desde que se convirtieron en hijos e hijas de "la generación robada". Esta idea coincide con numerosos estudios que han señalado el trauma histórico y la descripción de sentimientos de desposesión cultural, como consecuencia de la separación de su tierra de origen de los miembros de edad más avanzada de nuestro grupo, con la producción de un tipo de narrativa de nostalgia, expresada en términos de sufrimiento, sometimiento, despojo y falta de identidad, proporcionando un efecto negativo, en términos de bienestar, que se ha transmitido entre generaciones $^{(27,37,38,39)}$.

La historia colonial y el trauma intergeneracional que provocó han llegado a ser fundamentales en los programas de intervención psicosocial con población indígena en EEUU y Canadá, y también en población aborigen de Australia. Todo apunta a un efecto de cohorte que llega hasta nuestros días; la bibliografía describe cómo las actuales generaciones -algunos de los padres y madres y, sobre todo, la mayor parte de los hijos y nietos descendientes de la generación robada, nacida en contextos urbanos como el estudiado- siguen siendo más proclives a enfrentar situaciones de marginalidad y estilos de vida perjudiciales para la salud ${ }^{(40,41,42)}$. Estamos ante elementos que no solo conectan con situaciones de deprivación económica, sino también sociocultural, y que se manifiestan en una ausencia o deficiente estimulación en el desarrollo humano, que puede ser potencial causante de trastornos en la evolución de la personalidad, el aprendizaje y la socialización; situaciones de deprivación que caracterizan a comunidades, familias y personas en situación de vulnerabilidad como las estudiadas. La bibliografía pone de manifiesto cómo dichas vulnerabilidades a menudo se incrementan con el paso del tiempo ${ }^{(2,43)}$. En nuestro caso, el seguimiento efectuado a lo largo de cuatro años ha puesto de manifiesto una situación de escasa mejora de sus condiciones y calidad de vida, que se refleja, entre otros aspectos, en factores como la falta de participación en las instituciones sociales, la persistencia de un alto grado de dependencia y de sentimientos de marginalidad e inferioridad.

A pesar de que la experiencia colonial para los grupos indígenas en Australia no puede ser caracterizada como una experiencia homogénea, sino que presenta una considerable variabilidad regional, el relato de desposesión, opresión y nostalgia, que emerge con fuerza de los resultados, ofrece un marco interpretativo de intervención que puede ser clave a la hora de desarrollar 
intervenciones para reestructurar un yo, individual y colectivo, devaluado socialmente ${ }^{(44)}$.

Hoy día, la promesa de que una cultura indígena ancestral, como paradoja salutogénica, es capaz de tener eficacia simbólica en los programas comunitarios de intervención social, está logrando cierto éxito psicoterapéutico ${ }^{(45,46)}$. Como resultado, el número de programas de intervención que recurren a prácticas tradicionales ha aumentado considerablemente desde la década de 1990. Brady ${ }^{(47)}$, por ejemplo, mostró en su revisión bibliográfica sobre prácticas indígenas, cómo los enfoques grupales basados en enseñanzas tradicionales han llegado a ser dominantes en el área de tratamiento de las adicciones de alcohol y otras drogas. La integración de la historia colonial indígena, la cultura y los enfoques grupales en programas que intervienen con problemas psicosociales, permite a los individuos reconceptualizar su vida personal como "superviviente", escapando de la imagen de victimismo pasivo, producto de la opresión colonial.

Como se aprecia en nuestros resultados, los participantes focalizaron su situación social a través de un discurso colectivo que gira en torno al concepto de trauma histórico, que es introducido por factores como, por ejemplo, la pérdida de tierras ancestrales y de la lengua materna, o verse abocados a una cultura que consideran predominantemente individualista. En este sentido, Kirmayer ${ }^{(48)}$ sostiene que el trauma compartido por una comunidad entera crea un espacio público potencial para re-narrar. Un espacio público de trauma proporciona una realidad consensual y una memoria colectiva en la que los fragmentos de memoria personal pueden ser ensamblados, reconstruidos y mostrados como una asunción tácita de validez. Con independencia de factores personales o problemas psicosociales como adicciones, depresión, comportamientos violentos o actividades delictivas, estos fragmentos son articulados con frecuencia de acuerdo con la creencia de que el pasado colonial constituyó un momento crítico en la transformación de las sociedades indígenas. En este sentido, y como señalamos en los resultados, la idea de trauma colectivo funciona como estructura narrativa y metáfora colectiva para la compresión de problemas sociales contemporáneos.

Por su parte, Geertz ${ }^{(49)}$ expuso que los símbolos sagrados actúan para representar y formular concepciones de un orden general de existencia. Los símbolos sagrados representan una noción de la vida ideal contra la cual la producción de juicios morales es posible, proporcionando una guía normativa para la acción. En este sentido, la espiritualidad y la conexión con la tierra simbolizan el estado de salud y representan una vida ideal aborigen. Por tanto, los símbolos de salud y enfermedad constituyen el ethos de un colectivo humano, proporcionando tanto modelos ideales de orden social, como modelos para el mantenimiento y restablecimiento de dicho orden. De hecho, consistente con estas proposiciones, las narrativas mostradas en la sección de resultados reflejan juicios morales sobre modelos de vida ideal.

Nuestros resultados ponen de manifiesto que, pese a que el grupo de aborígenes participantes en el estudio no manifiestan tener un conocimiento profundo de sus tradiciones, ceremonias y ritos ancestrales, estos están fuertemente incorporados a su imaginario colectivo. Concretamente, los resultados apuntan, en consonancia con lo descrito en otros estudios ${ }^{(50)}$, a que dicho imaginario está enraizado en una visión de interdependencia con el mundo natural y el mundo de las relaciones familiares. Esto se refleja, por ejemplo, en la importancia concedida como fuente de bienestar a la realización de actividades tradicionales. En el caso de las poblaciones jóvenes, existe un corpus creciente de evidencias de que la participación en las actividades tradicionales no solo puede contribuir a fortalecer los lazos familiares, sino que puede ser un factor protector para la salud, especialmente para la depresión y el abuso de sustancias ${ }^{(51)}$. Este hallazgo es también consistente con la revisión sistemática sobre programas de intervención cultural elaborada por Maclean ${ }^{(19)}$ : de los 11 programas analizados, 10 mostraron que la inclusión de componentes culturales para facilitar 
la expresión de la identidad cultural tenía efectos positivos para la salud y bienestar. Por otro lado, los resultados de la evaluación de programas dirigidos a estas poblaciones apuntan claramente a que, para alcanzar niveles óptimos de implementación del programa y efectividad en los indicadores de resultado, deben estar diseñados con un fuerte componente cultural ${ }^{(52,53,54)}$. En este sentido, resultan de especial interés la implicación en actividades como narración de cuentos, canciones, danzas, pinturas nativas, no solo porque se trata de manifestaciones artísticas que generan un vínculo directo con la cultura de sus ancestros, sino que facilitan que adquieran protagonismo, lo que contribuye a aumentar la adherencia y la satisfacción con el programa ${ }^{(17,24)}$, además de constituirse en elementos clave para mejorar los niveles de autoestima y el desarrollo de la capacidad de empoderamiento ${ }^{(55)}$. No hay que olvidar que las actividades culturales también suelen promover sentimientos de pertenencia y activar otros recursos que, como el apoyo social, son favorecedores para la salud y el bienestar ${ }^{(33)}$.

Entre otros factores relacionados con el capital cultural que pueden estar influyendo en esta situación, se encuentra el impacto que produce la percepción de pérdida progresiva de la lengua materna y el vínculo con su espiritualidad. Nuestros resultados indican, en consonancia con otros estudios, que ambos elementos se constituyen en un vínculo identitario clave a la hora de analizar el sentimiento de desarraigo de los aborígenes que residen en zonas urbanas de Austra$\mathrm{lia}^{(56)}$. Atendiendo a nuestros resultados, solo hemos encontrado un caso de un adulto que afirmaba mantener una espiritualidad tradicional, retornando cada cierto tiempo a su lugar de origen para algunas celebraciones y rituales. Se trata de un aspecto que vincula directamente el capital cultural con la salud; de hecho, la bibliografía ha puesto de manifiesto la influencia positiva entre la conexión con la tierra y el desarrollo de estilos de vida más saludables, que se manifiestan en mejores resultados en factores de riesgo como obesidad, inactividad física o consumo nocivo de drogas, e incluso menores tasas de hospitalización entre los propios aborígenes $^{(57)}$.

Muchos de estos problemas se quedan incrustados en la estructura social como una discriminación institucionalizada, que se manifiesta habitualmente en indicadores de desempleo o pobreza ${ }^{(58)}$. De forma general, la investigación epidemiológica sugiere que las personas con desventajas socioeconómicas pueden ser menos propensas a percibir desigualdades socialmente estructurales ${ }^{(59)}$. Observamos cómo las familias seguidas durante el periodo de estudio identifican algunos de los factores que les han llevado a sus condiciones de vida actuales, si bien lo más significativo es que, de forma generalizada, no se observa que tengan habilidades sociales y competencias para la acción, incluidas las habilidades operativas para afrontar y resolver sus propios problemas y necesidades.

Entre las limitaciones observadas del programa que ha sido el hilo conductor de este estudio, se encuentra la escasa participación en la autogestión del programa de los aborígenes, destinatarios de sus actividades. Diferentes estudios han mostrado cómo la participación activa en programas comunitarios puede contribuir a la mejora tanto del grupo como del individuo, pudiendo incidir positivamente en el abordaje de problemáticas como la violencia familiar, el control de la diabetes o en la prevención del suicidio $y$ el consumo de sustancias nocivas ${ }^{(24,60)}$. Sin embargo, según nuestras observaciones de campo, las personas organizadoras y voluntarias del programa tendían a desestimar esta posibilidad. Esto resta posibilidades al desarrollo de la capacidad de autonomía y toma de decisiones ${ }^{(61)}$. Estamos ante competencias y habilidades cognitivo-operativas que no solo han sido relacionadas con el crecimiento personal y el desarrollo de bienestar, sino también con la posibilidad de participar de manera efectiva como miembro activo de una comunidad ${ }^{(62,63,64)}$. En el caso concreto de programas como en el que se participó, esto contribuye a generar una respuesta instrumental y asistencialista, por parte de las familias aborígenes, para beneficiarse de una serie de recursos y gestiones que, en 
definitiva, pueden estar siendo una barrera para generar un mayor nivel de desarrollo humano y capacidad de integración social.

Por otro lado, los resultados ponen de manifiesto que, para los jóvenes, la adaptación al contexto dominante y la búsqueda de perspectivas de futuro pasa, en buena medida, por una mayor socialización que permita superar estigmas raciales. Para ello, nuestros hallazgos apuntan claramente a la consecución de prestigio social a través de prácticas como el footy. En este sentido, otros estudios también lo han considerado un factor positivo en la forja de la identidad, la cohesión social y el sentido de pertenencia entre los propios aborígenes ${ }^{(65,66,67)}$. En consonancia con nuestros resultados, esto tiene que ver con el hecho de que los atletas aborígenes cada vez cuentan con un mayor reconocimiento por su contribución al éxito deportivo de Australia, lo que adquiere aún especial significado en contextos de racismo latente y oportunidades restringidas para las minorías étnicas ${ }^{(68)}$. Precisamente, en este sentido, las familias aborígenes consultadas expresaron la falta de apoyo adicional para sus hijos, lo que también estaría poniendo de manifiesto una carencia institucional de atención a la diversidad, a través de la actividad físico-deportiva de los grupos menos favorecidos ${ }^{(69,70)}$.

\section{Limitaciones}

En términos generales, la investigación etnográfica persigue describir, interpretar y comprender la vida de las personas; los significados que estas dan a los eventos que experimentan en ambientes sociales particulares, y las distintas formas de dar sentido a sus vidas. De esta manera, siguiendo los preceptos de la investigación etnográfica, a lo largo de este trabajo hemos tratado de comprender la experiencia humana desde la perspectiva de los propios actores sociales. En este sentido, los verbatims que aparecen en este artículo sirven para apoyar la identificación de temas e ideas claves, siendo conscientes de las limitaciones que ello comporta a la hora de captar la riqueza de la experiencia subjetiva de las personas participantes. En cualquier caso, consideramos que el estudio contribuye a la práctica basada en la evidencia, puesto que los resultados pueden examinarse como barreras y facilitadores, y contribuir a mejorar el diseño de programas sociocomunitarios con poblaciones indígenas y/o minorías étnicas ${ }^{(71)}$.

\section{CONCLUSIONES}

Nuestros resultados, basados en el seguimiento en un programa comunitario dirigido a un grupo de familias aborígenes residentes en la ciudad de Sídney, ponen de manifiesto la importancia de basar los programas de intervención en componentes tradicionales. En el caso concreto de nuestro estudio, los resultados son una contribución a la idea del significativo impacto que los procesos sociohistóricos colonizadores han causado en los aborígenes consultados; especialmente, en lo que respecta a la pérdida de la lengua materna y su relación con la tierra y espiritualidad; factores indicativos de un proceso de desarraigo cultural que deja entrever que estamos ante la causa de las causas de las experiencias vitales de desigualdad social que han determinado sus vidas, y continúan condicionando la de sus hijos. Por tanto, dicha (des)consonancia cultural debe ser tenido en cuenta como un factor clave a la hora de analizar las condiciones de vida y bienestar de estas minorías étnicas.

Un programa que pretende contribuir a la mejora de la calidad de vida de familias como las participantes en este estudio, requiere un conocimiento más profundo de las interacciones que se dan entre el capital cultural, social y económico dentro de estas familias. Avanzar en el entendimiento de estas formas de capital no solo contribuiría a entender mejor cómo las creencias, conocimientos, valores y normas de comportamiento cambian y persisten en estas poblaciones, sino que este enfoque también ayudaría a mejorar nuestra comprensión de por qué algunas intervenciones tienen éxito, mientras que otras fracasan. 


\section{AGRADECIMIENTOS}

Los autores expresan su agradecimiento más sincero a las familias participantes de la comunidad aborigen del centro de Sídney, por el alto grado de colaboración durante los cuatros años en los que se desarrolló la investigación. También a la asociación de voluntarios, por toda la ayuda prestada durante todo este tiempo. Además, queremos agradecer al profesor Ángel Acuña Delgado de la Universidad de Granada (España), por sus recomendaciones y comentarios durante el proceso de desarrollo del proyecto.

\section{REFERENCIAS BIBLIOGRÁFICAS}

1. Bombay A, Matheson K, Anisman H. Appraisals of discriminatory events among adult offspring of Indian residential school survivors: The influences of identity centrality and past perceptions of discrimination. Cultural Diversity \& Ethnic Minority Psychology. 2016;20(1):75-86. doi: 10.1037/a0033352.

2. Kirmayer LJ, Gone JP, Moses J. Rethinking historical trauma. Transcultural Psychiatry. 2014;51(3):299-319. doi: $10.1177 / 1363461514536358$

3. Gallaher G, Ziersch A, Baum F, Bentley M, Palmer C, Edmondson W, Winslow L. In our own backyard: Urban health inequities and Aboriginal experiences of neighbourhood life, social capital and racism. Adelaide: Flinders University; 2009.

4. Australian Institute of Health and Welfare. Australia's health 2018 [Internet]. Canberra: AlHW; 2018 [citado 21 sep 2018]. Disponible en: https://tinyurl.com/y2u2do8q.

5. Australian Institute of Health and Welfare. Aboriginal and Torres Strait Islander Health Performance Framework Report 2017 [Internet]. Canberra: AlHW; 2017 [citado 21 sep 2018]. Disponible en: https://tinyurl.com/y6ujzc65.

6. Commonwealth of Australia (Internet). Closing the gap: Prime Minister's report 2016 [Internet]. Canberra: Commonwealth of Australia; 2016 [citado 21 nov 2016]. Disponible en: https://tinyurl.com/y72lf3xg.

7. Australian Bureau of Statistics. Prisoners in Australian [Internet]. Canberra: Commonwealth of Australia; 2019 [citado 11 abr 2019]. Disponible en: https://tinyurl.com/ y8tqf2vh.

8. Berkman LF, Kawachi I, Glymour MM, (eds.). Social epidemiology. Oxford University Press; 2014.

9. Marmot $M$. The health gap: the challenge of an unequal world. The Lancet. 2015;386(10011):24422444. doi: 10.1016/S0140-6736(15)00150-6.

10. Zubrick SR, Shepherd CJ, Dudgeon P, Gee G, Paradies $Y$, Scrine $C$, et al. Social determinants of social and emotional wellbeing. In: Dudgeon P, Milroy $\mathrm{H}$, Walker $\mathrm{R}$, (eds.). Working together: Aboriginal and Torres Strait Islander mental health and wellbeing principles and practice. Perth: Telethon Institute for Child Health Research \& Canberra, Australian Government Department of the Prime Minister and Cabinet; 2014. p. 93-112.
11. Swain S. Transitional justice workers and vicarious trauma. En: Johanna Sköld J, Swain S, (eds.). Apologies and the Legacy of Abuse of Children in 'Care'. London: Palgrave Macmillan; 2015. p. 181-190.

12. McMillan M, McRae C. Law, identity and dispossession - the Half-Caste Act of 1886 and Contemporary Legal Definitions of Indigeneity in Australia. En: McMillan M, McRae C, (eds.). Indigenous communities and settler colonialism. London: Palgrave Macmillan; 2015. p. $233-244$

13. Flood J, Wylie D. The original Australians: Story of the aboriginal people crows nest. Australia: Allen \& Unwin; 2006.

14. Rowse T. Historical reasoning about Indigenous imprisonment: A community of fate. Australian Review of Public Affairs. 2015;13(1):1-21.

15. McKnight D. From hunting to drinking: The devastating effects of alcohol on an Australian Aboriginal community. London: Routledge; 2002.

16. Macdonald D, Abbott R, Jenkins D. Physical activity of remote Indigenous Australian women: A postcolonial analysis of lifestyle. Leisure Sciences. 2012;34(1):39-54. doi: 10.1080/01490400.2012.633854.

17. Kerpan S, Humbert L. Playing together: Playing Together: The physical activity beliefs and behaviors of urban Aboriginal youth. Journal Physical Activity \& Health. 2015;12(10):1409-1413. doi: 10.1123/jpah.2014-0533.

18. Macniven R, Elwell M, Ride K, Bauman A, Richards J. A snapshot of physical activity programs targeting Aboriginal and Torres Strait Islander people in Australia. Health Promotion Journal of Australia. 2017;28(3):185206. doi: 10.1071/HE16036.

19. MacLean S, Ritte R, Thorpe A, Ewen S, Arabena K. Health and wellbeing outcomes of programs for Indigenous Australians that include strategies to enable the expression of cultural identities: a systematic review. Australian Journal of Primary Health. 2017;23(4):309318. doi: 10.1071/PY16061.

20. Fitzpatrick EF, Oscar J, Carter M, Lawford T, Martiniuk AM, D'Antoine $\mathrm{H}$, Elliott $E \mathrm{~J}$. Conducting research together with remote Aboriginal communities. In: 14th National Rural Health Conference: A World of Rural Health. Canberra: National Rural Health Alliance; 2017.

21. Evans JR, Wilson R, Coleman C, Man WYN, Olds T. Physical activity among indigenous Australian children and youth in remote and non-remote areas. Social Science \& Medicine. 2018;206:93-99. doi: 10.1016/j. socscimed.2018.04.018.

22. Dalton B, Wilson R, Evans JR. Cochrane S. Australian Indigenous youth's participation in sport and associated health outcomes: Empirical analysis and implications. Sport Management Review. 2015;18(1):57-68. doi: 10.1016/j.smr.2014.04.001.

23. Poortinga W. Community resilience and health: The role of bonding, bridging, and linking aspects of social ca- 
pital. Health \& Place. 2012;18(2):286-295. doi: 10.1016/j. healthplace.2011.09.017.

24. Chandler MJ. Lalonde CE. Cultural continuity as a moderator of suicide risk among Canada's First Nations. In: Kirmayer L, Valaskakis G, (eds.). Healing traditions: The mental health of Aboriginal peoples in Canada. Vancouver: University of British Columbia Press; 2008. p. 221-248.

25. Fiedeldey-Van Dijk C, Rowan M. Dell C. Mushquash C, Hopkins C, Fornssler B, Shea B. Honoring Indigenous culture-as-intervention: Development and validity of the Native Wellness AssessmentTM. Journal of Ethnicity of Substance Abuse. 2017;16(2):181-218. doi: 10.1080/15332640.2015.1119774.

26. Naquin V, Trojan J, O'Neil G, Manson SM. The Therapeutic Village of Care: an Alaskan Native alcohol treatment model. Therapeutic Communities. 2006;27(1):107-123.

27. Marquina-Márquez A, Virchez J, Ruiz-Callado R. Postcolonial healing landscapes and mental health in a remote Indigenous community in subarctic Ontario, Canada. Polar Geography. 2016;39(1):20-39. doi: 10.1080/1088937X.2016.1155673.

28. Do P, Finch B. The Link between Neighborhood Poverty and Health: Context or Composition? American Journal of Epidemiology. 2008;168(6):611-619. doi: 10.1093/aje/kwn182.

29. Krieger J, Higgins D. Housing and health: Time again for public health action. American Journal of Public Health. 2002;92(5):758-768. doi: 10.2105/ajph.92.5.758.

30. Poortinga W, Dunstan F D, Fone D L. Neighbourhood deprivation and self-rated health: The role of perceptions of the neighbourhood and of housing problems. Health \& Place. 2008;14(3):562-575. doi: 10.1016/j. healthplace.2007.10.003.

31. Ferguson KM. Social capital and children's wellbeing: a critical synthesis of the international social capital literature. International Journal of Social Welfare. 2006;15(1):2-18. doi: 10.1111/j.1468-2397.2006.00575.x.

32. Lechner N. Desafíos de un desarrollo humano: individualización y capital social. Instituciones y Desarrollo. 2000;(7):7-34

33. Abel T. Cultural capital and social inequality in health. Journal of Epidemiology \& Community Health. 2008;62(7):e13. doi: 10.1136/jech.2007.066159.

34. Hsieh HF, Shannon SE. Three approaches to qualitative content analysis. Qualitative Health Research. 2005; 15:1277-88.

35. Australian Government. Privacy and Personal Information Protection Regulation Act 2005 [Internet]. 2014 [citado 10 may 2019]. Disponible en: https://tinyurl. com/y7cf7phd.

36. Gobierno de España. Ley Orgánica 15/1999, de 13 de diciembre, de Protección de Datos de Carácter Per- sonal. Boletín del Estado. 1999;298(2):43088-43099.

37. Griffiths K, Coleman C, Lee V, Madden R. How colonization determines social justice and Indigenous health-a review of the literature. Journal of Population Research. 2016;33(1):9-30.

38. Adelson N. "Being Alive Well": Health and the Politics of Cree Well-Being. Toronto: University of Toronto Press; 2004

39. Quintero G. Nostalgia and degeneration: The moral economy of drinking in Navajo Society. Medical AnthropologyQuarterly.2002;16(1):3-21.doi:10.1525/maq.2002. 16.1.3.

40. Haebich A. Neoliberalism, settler colonialism and the history of indigenous child removal in Australia. Australian Indigenous Law Review. 2015;19(1):20-31.

41. Kenny C, Ngaroimata T, (eds.). Living indigenous leadership: Native narratives on building strong communities. Vancouver: UBC Press; 2013

42. Peet J L. Institutional ethnography of Aboriginal Australian child separation histories: implications of social organizing practices in accounting for the past. [Doctoral dissertation]. Edinburgh: University of Edinburgh; 2014.

43. Reid P, Cormack D, Paine SJ. Colonial histories, racism and health - The Experience of Maori and indigenous peoples. Public Health. 2019;172:119-124. doi 10.1016/j.puhe.2019.03.027.

44. Stromberg P. Language and self-transformation: a study of the Christian conversion narrative. Cambridge University Press, Cambridge; 2008.

45. Brass GM. Respecting the medicines: Narrating an aboriginal identity. In: Kirmayer L, Vlaskakis G. Healing traditions: The mental health of Aboriginal peoples in Canada. Vancouver: UBC Press; 2008. p. 355-380.

46. Waldram J. The way of the pipe: Aboriginal spirituality and symbolic healing in Canadian prisons. Toronto: University of Toronto Press; 1997.

47. Brady M. Culture in treatment, culture as treatment: A critical appraisal of developments in addictions programs for indigenous North Americans and Australians. Social Science \& Medicine.1995;41(11):1487-1498. doi: 10.1016/0277-9536(95)00055-c.

48. Kirmayer L, Vlaskakis, G. Healing Traditions: The mental health of aboriginal peoples in Canada. Vancouver: University of British Columbia Press; 2008.

49. Geertz C. La interpretación de las culturas. Barcelona: Gedisa; 2003.

50. Ridani R, Shand FL, Christensen H, McKay K, Tighe J, Burns J, Hunter E. Suicide prevention in Australian Aboriginal communities: a review of past and present programs. Suicide and Life-Threatening Behavior. 2015;45(1):111140. doi: 10.1111/sltb.12121.

51. Rae $\mathrm{R}$, Jones $\mathrm{M}$, Handal $\mathrm{AJ}$, Bluehorse-Anderson M, Frazier S, Maltrud K, Percy C, Tso T, Varela F, Wa- 
Ilerstein N. Healthy native community fellowship: An Indigenous leadership program to enhance community wellness. The International Indigenous Policy Journal. 2016;7(4):2. doi: 10.18584/iipj.2016.7.4.2.

52. Goslett M, Beavan V. Ngara Dyin: Listening to Aboriginal women of the Illawarra and Shoalhaven. International Journal of Critical Indigenous Studies. 2017;10(1):1-16.

53. Dudgeon P, Calma T, Holland C. The context and causes of the suicide of Indigenous people in Australia. Journal of Indigenous Wellbeing. 2017;2(2):5-15.

54. Morley S R. What works in effective Indigenous community-managed programs and organizations. Melbourne: Australian Institute of Family Studies; 2005.

55. Stajic J, Harfield S, Brown A, Dawson A, Davy C, Aromataris E, Braunack-Mayer A. Evaluating a research capacity strengthening program for Aboriginal community-controlled health organizations. Australian Journal of Primary Health. 2019;25(1):72-81. doi: 10.1071/PY18058.

56. Australian Bureau of Statistics. Australian Aboriginal and Torres Strait Islander Health Survey: Updated Results 2012-13 [Internet]. 2014 [citado 10 jul 2018]. Disponible en: https://tinyurl.com/yclqk6oj.

57. Schultz R, Cairney S. Caring for country and the health of Aboriginal and Torres Strait Islander Australians. The Medical Journal of Australia. 2017;207(1):8-10.

58. Mellor D, McCabe M, Ricciardelli L, Mussap A, Tyler M. Toward an understanding of the poor health status of Indigenous Australian men. Qualitative Health Research. 2016;26(14):1949-1960. doi: $10.1177 / 1049732315609898$.

59. Macintyre S, McKay L, Ellaway A. Who is more likely to experience common disorders: man, women, or both equally? Lay perceptions in the West of Scotland. International Journal of Epidemiology. 2005;34(2):461-466. doi: 10.1093/ije/dyh333.

60. Doyle J, Firebrace B, Reilly R, Crumpen T, Rowley K. What makes us different?: The role of Rumbalara Football and Netball Club in promoting Indigenous wellbeing. The Australian Community Psychologist. 2013;25(2):7-21.

61. Walker R, Shepherd C. Strengthening Aboriginal family functioning: What works and why? [Internet].
2008 [citado 22 feb 2018]. Disponible en: https://tinyurl. com/y9n5rppe.

62. Atinga RA, Agyepong I A, Esena R K. Willing but unable? Extending theory to investigate community capacity to participate in Ghana's community-based health planning and service implementation. Evaluation Program Planning. 2019;72:170-178. doi: 10.1016/j. evalprogplan.2018.10.001.

63. Reilly L, Rees S. Fatherhood in Australian Aboriginal and Torres Strait Islander communities: An examination of barriers and opportunities to strengthen the male parenting role. American Journal of Men's Health. 2018;12(2):420-430. doi: 10.1177/1557988317735928.

64. Carpiano RM. Neighbourhood social capital and adult health: An empirical test of a Bourdieu-based model. Health \& Place. 2007;13(3):639-655. doi: 10.1016/j. healthplace.2006.09.001.

65. Bruner B, Chad K. Physical activity attitudes, beliefs, and practices among women in a Woodland Cree community. Journal of Physical Activity \& Health. 2013;10(8):1119-1127. doi: 10.1123/jpah.10.8.1119.

66. Bamblett L. Our stories are our survival. Canberra: Aboriginal Studies Press; 2013.

67. Warner S, Leierer S. Building community via sport for adolescents. Journal of Applied Sport Management 2015;7(4). doi: 10.18666/JASM-2015-V7-I4-5994.

68. Klugman M, Osmond G. Black and proud: the story of an iconic AFL photo. Sydney: University of New South Wales Press; 2014.

69. Shiell A, Hawe P, Kavanagh S. Evidence suggests a need to rethink social capital and social capital interventions. Social Science \& Medicine. 2018;111930. doi: 10.1016/j.socscimed.2018.09.006.

70. Evans JR, Wilson R, Dalton B, Georgakis S. Indigenous participation in Australian sport: The perils of the 'panacea' proposition. Cosmopolitan Civil Societies: an Interdisciplinary Journal. 2015;7(1):53-77. doi: 10.5130/ ccs.v7i1.4232.

71. Pelcastre-Villafuerte B, Meneses-Navarro S, RiveraDommarco J. Programa Institucional Salud de los Pueblos Indígenas: agenda para la investigación, la docencia y la vinculación. Salud Pública de México. 2020;62: 228-230. doi: 10.21149/10992.

\section{FORMA DE CITAR}

Recibido: 31 ago 2019 | Versión final: 4 abr 2020 | Aprobado: 14 abr 2020 | Publicado en línea: 26 may 2020

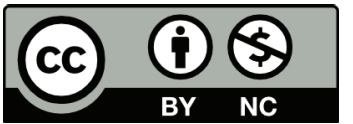

Esta obra está bajo una licencia de Creative Commons Reconocimiento-NoComercial 4.0

Internacional. Reconocimiento - Permite copiar, distribuir y comunicar públicamente la obra.

A cambio, se debe reconocer y citar al autor original. No Comercial - Esta obra no puede ser

utilizada con finalidades comerciales, a menos que se obtenga el permiso. 